\title{
Extracorporeal polypectomy of a large rectal polyp
}

Endoscopic polypectomy of large rectal polyps located close to the anal canal is a technical challenge for endoscopists [1]. It is sometimes impossible to use endoscopic techniques to remove the polyp and the patients are referred for surgical treatment [2].

A 66-year-old woman was evaluated for abdominal pain and rectal bleeding. She had a rectal mass that occasionally prolapsed through the anal canal. Colonoscopic examination revealed a large, pedunculated rectal polyp, located $2 \mathrm{~cm}$ proximal to the dentate line ( $\bullet$ Fig. 1). The polyp was $6 \mathrm{~cm}$ in size and had long stalk ( Fig. 2). Other colon segments were normal. Endoscopic polypectomy was planned. However, there was limited room to maneuver a polypectomy snare over the head of the large polyp, and it was manually pulled out of the anus ( $\bullet$ Fig. 3). The stalk was ligated with a silk suture. To avoid thermal damage to the lining of the anal canal, nonconductive plastic material was inserted between the polyp and the anal canal. The polypectomy snare (Microvasive Endoscopy, Boston Scientific International, La Garenne Colombes, France) was then located on the stalk and external polypectomy successfully carried out by using the polypectomy snare and electrosurgical current ( Fig. 4). There was no pain or bleeding during or after the procedure. Histologic examination of the polyp revealed tubulovillous adenoma with highgrade dysplasia.

Aydin et al. were the first to report the use of external polypectomy to remove a giant rectal polyp [3]. Tony et al. externally resected a giant sigmoid lipoma that was causing colonic intussusception and had prolapsed through the anal canal [4]. Leung et al. used external polypectomy to remove a large rectal polyp after polyloop detectable snare ligation [5]. In the present case, extraction of the polyp through the anal canal allowed us to ligate the stalk securely and remove the large polyp completely. Giant pedunculated rectal polyps may be removed securely by extracorporeal polypectomy instead of surgical resection.

Endoscopy_UCTN_Code_TTT_1AQ_2AD

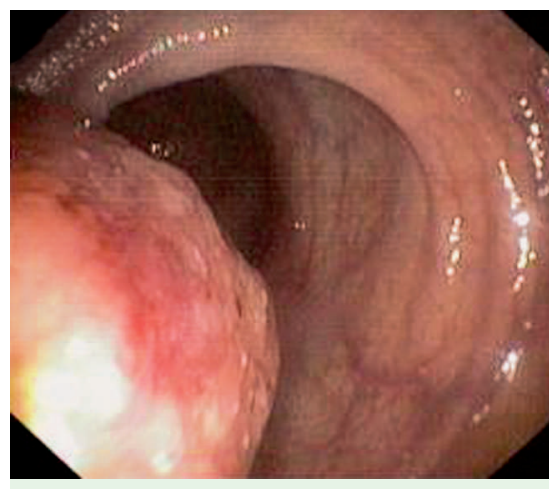

Fig. 1 Rectal polyp located close to the anal canal.

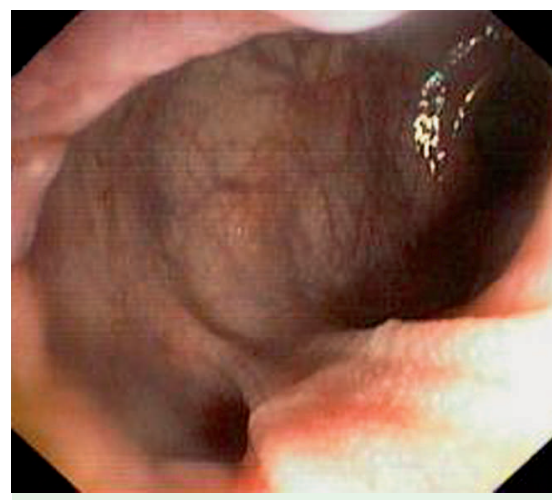

Fig. 2 The long stalk of the polyp.

\section{N. Oruc, O. Ozutemiz, A. Musoglu,} T. Ilter

Ege University, Faculty of Medicine, Department of Gastroenterology, Izmir, Turkey

\section{References}

1 Iishi $H$, Tatsuta $M$, Narahara $H$ et al. Endoscopic resection of large pedunculated colorectal polyps using a detachable snare. Gastrointest Endosc 1996; 44: $594-597$

2 Voloyiannis T, Snyder MJ, Bailey RR et al. Management of the difficult colon polyp referred for resection: resect or rescope? Dis Colon Rectum 2008; 51: 292-295

3 Aydin A, Musoglu A, Ersoz G et al. Extracorporeal polypectomy. Endoscopy 1997; 29: $57-58$

4 Tony J, Saji S, Sandesh Ket al. External resection of a giant sigmoid lipoma causing colonic intussusception and prolapse through the anal canal. Trop Gastroenterol 2007; 28: $127-128$

5 Leung KK, Yusuf TE. External polypectomy of a large anal canal polyp. Gastrointest Endosc 2007; 66: 603

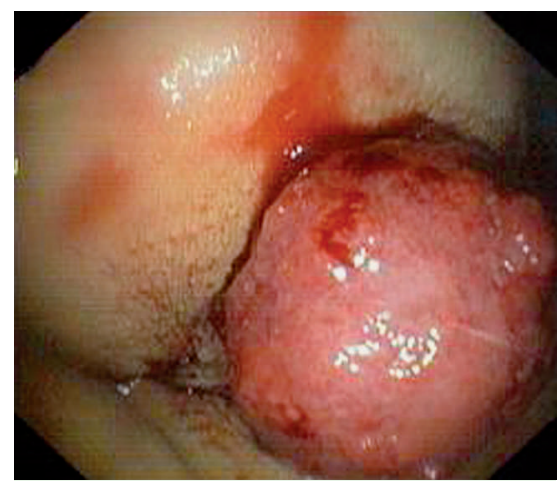

Fig. 3 The $6 \mathrm{~cm}$ polyp being manually pulled out of the anal canal.

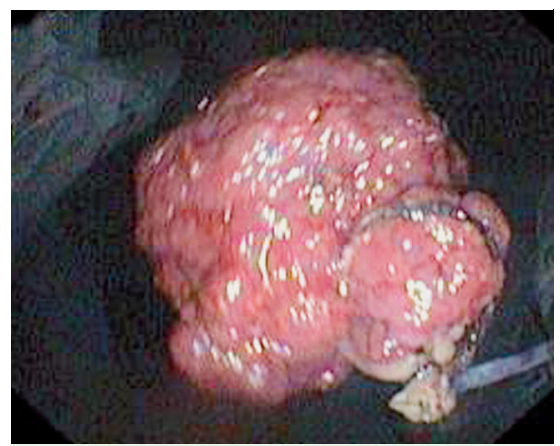

Fig. 4 Extracorporeal polypectomy carried out successfully.

Bibliography

DOI 10.1055/s-0029-1214803

Endoscopy 2009; 41: E198

(c) Georg Thieme Verlag KG Stuttgart · New York . ISSN 0013-726X

Corresponding author

\section{N. Oruc}

Ege University Faculty of Medicine Gastroenterology Department

Bornova, Izmir 35100

Turkey

Fax: +90-232-3745761

nevintr@yahoo.com 